\title{
Predictors of Physician Compassion, Empathy, and Related Constructs: a Systematic Review
}

\author{
Alina Pavlova, MSc, MA®D, Clair X. Y. Wang, MBChB (Hons), Anna L. Boggiss, PGDipHSc, \\ Anne O'Callaghan, M.D., and Nathan S. Consedine, PhD
}

Faculty of Medical and Health Sciences, Department of Psychological Medicine, The University of Auckland, Building 507, 3, Auckland, New Zealand.

BACKGROUND: Compassion in healthcare provides measurable benefits to patients, physicians, and healthcare systems. However, data regarding the factors that predict care (and a lack of care) are scattered. This study systematically reviews biomedical literature within the Transactional Model of Physician Compassion and synthesizes evidence regarding the predictors of physician empathy, compassion, and related constructs (ECRC).

METHODS: A systematic literature search was conducted in CENTRAL, MEDLINE, PsycINFO, EMBASE, CINAHL, AMED, OvidJournals, ProQuest, Web of Science, and Scopus using search terms relating to ECRC and its predictors. Eligible studies included physicians as participants. Methodological quality was assessed based on the Cochrane Handbook, using ROBINS-I risk of bias tool for quantitative and CASP for qualitative studies. Confidence in findings was evaluated according to GRADE-CERQual approach.

RESULTS: One hundred fifty-two included studies (74,866 physicians) highlighted the diversity of influences on compassion in healthcare (54 unique predictors). Physician-related predictors (88\%) were gender, experience, values, emotions and coping strategies, quality of life, and burnout. Environmental predictors $(38 \%)$ were organizational structure, resources, culture, and clinical environment and processes. Patient-related predictors (24\%) were communication ease, and physicians' perceptions of patients' motives; compassion was also less forthcoming with lower SES and minority patients. Evidence related to clinical predictors (15\%) was scarce; high acuity presentations predicted greater ECRC.

DISCUSSION: The growth of evidence in the recent years reflects ECRC's ongoing importance. However, evidence remains scattered, concentrates on physicians' factors that may not be amenable to interventions, lacks designs permitting causal commentary, and is limited by selfreported outcomes. Inconsistent findings in the direction of the predictors' effects indicate the need to study the relationships among predictors to better understand the mechanisms of ECRCs. The current review can guide future research and interventions.

Received April 9, 2021

Accepted July 20, 2021

Published online September 20, 2021
J Gen Intern Med 37(4):900-11

DOI: $10.1007 / \mathrm{s} 11606-021-07055-2$

(C) Society of General Internal Medicine 2021

\section{BACKGROUND}

Compassion - defined as noticing the suffering of another and being motivated to alleviate it ${ }^{1}$ - is an important healthcare characteristic $^{2}$ that predicts better patient outcomes ${ }^{3-11}$, and is associated with better physician quality of life ${ }^{12,13}$. A lack of compassion has been linked to decreased patient well-being $^{9,14,15}$ and a loss of professional motivation ${ }^{16-20}$. While a systemic lack of compassion in healthcare has been noted ${ }^{21,22}$, studies specific to medical compassion are scarce ${ }^{23-26}$ with most research focused on related constructs such as empathy and caring.

A scoping review by Sinclair and colleagues ${ }^{27,28}$ identified a number of personal, relational, and organizational factors as relevant to compassionate care. The purpose of our review is to identify the predictors of both compassion and related constructs such as empathy, caring behavior, and personand patient-centered care (referred to conjointly as "empathy, compassion, and related constructs" (ECRC)) to better characterize the research foci in the area of prosocial feelings and behavior in patient care, to assess the extent to which findings are consistent, to assess studies' quality, and to evaluate the extent to which the factors predicting compassion are different or similar to factors predicting related constructs.

\section{METHODS}

The review was conducted in accordance with PRISMA guidelines $^{29}$, and was pre-registered on PROSPERO (ID: 177815). The search strategy was devised in consultation with a medical librarian and conducted on the 24th of April 2020 using Cochrane Library (including CENTRAL), MEDLINE, EMBASE, PsycINFO, CINAHL, AMED, OvidJournals, ProQuest, Web of Science, and Scopus. We used a combination of subheadings (MeSH terms/EMTREEs) and keywords using (1) context-defining terms (e.g., physician, healthcare), (2) ECRCs (e.g., empathy, compassion, motivation to help-see eSupplement 1 for the ECRC constructs selection rationale), 


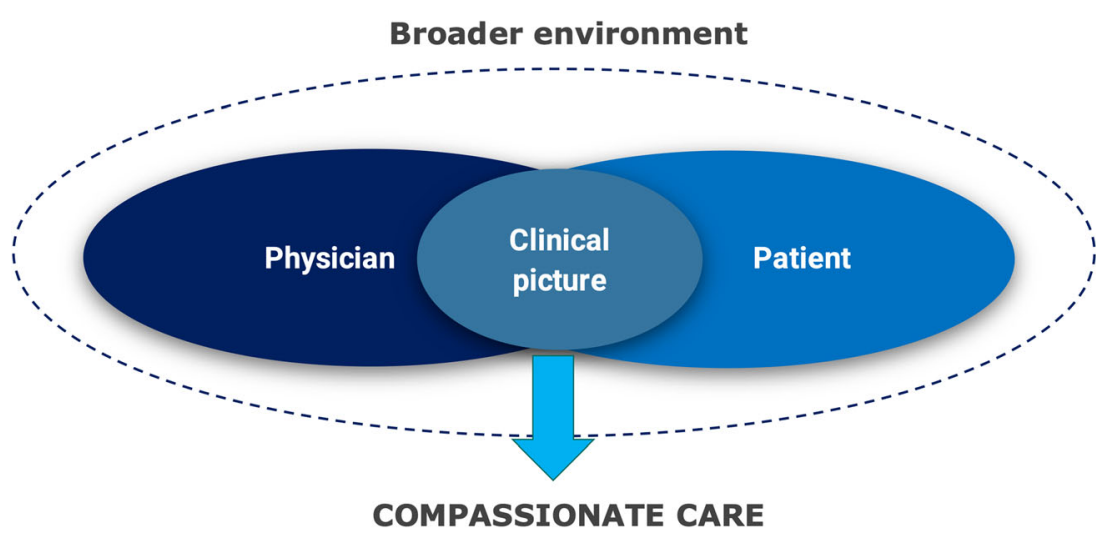

Figure 1 The Transactional Model of Physician Compassion (TMPC): Transactional Model suggests that whether a physician will behave compassionately in any given instance reflects the dynamic influences of physician, patient, clinical, and environmental factors.

and (3) keywords that denote factors (e.g., "factor_", "facilitat_", "barrier_"). The search strategy was developed, piloted, and refined in EMBASE (See eSupplement 2) and then applied to other databases in accordance with the functionality. Reference checks and forward citation searches for the selected studies were implemented. Peer-reviewed journal articles and gray literature such as dissertations and industry or government reports that focused on factors predicting ECRC were included.

Inclusion criteria included studies that focused on physicians or residents/registrars/graduate trainees (according to legislation) (MD/DO) of any specialty except dentistry and pharmacy where the primary method of data collection was either physicians' self-report or observation by an independent observer. Other medical professionals, such as nurses and allied health professionals (e.g. psychologists), were excluded.

We excluded publications that were not in English, not peer-reviewed, or where the level of peer review was uncertain (commentaries, editorials, and perspectives, etc.). Studies based on patient report were excluded due to nonindependence from possible patient confounding factors. Interventions were excluded due to the multifactorial nature limiting the possibility to identify specific factors predicting ECRC. No restrictions were imposed on studies' date, research design, or methodological limitations. Excluded studies can be found in the eSupplement 14 .

\section{Data Collection and Analysis}

All identified records were de-duplicated in EndNote and the screening was conducted in two steps-(1) two coders (A. P. and C. W.) independently screened the titles and abstracts on Rayyan $^{30}$ before (2) two coders (A. P. and C. W.) independently assessed full texts of selected records against the inclusion criteria. Any disagreements were resolved through discussion and/or consultation with a third reviewer (N. C.). The data were extracted by two coders independently (A. P. and A. B.) via pre-defined data extraction forms (See eSupplement 3). The evidence was synthesized via framework thematic synthesis approach ${ }^{31}$ according to Transactional Model of
Physician Compassion (TMPC) physician, patient and family, environmental, and clinical domains (Fig. 1) ${ }^{23,32}$. Data from studies based on the same sample and methods were collated to avoid double-counting.

The effects of the factors on ECRC were summarized in terms of direction as well as narratively. Positive or negative predictors were grouped if these had at least moderate significant positive or negative effect $(p<0.05)$ when prespecified confounders (gender, experience) were considered. For qualitative studies, only the data from direct quotes were used, to ensure we used "first-order constructs" 33 .

\section{Quality Assessment}

Risk of bias was assessed independently by two coders (A. P. and A. B.). In the case of a disagreement, consensus was reached by discussion with the third reviewer (N. C. $)^{34}$. Quantitative studies were assessed by an adaptation of ROBINS-I tool $^{35}$, qualitative studies by CASP ${ }^{36}$. The GRADE-CERQual approach was applied to assess confidence in the review findings ${ }^{31,37}$. The authors with clinical experience have reviewed the validity and clinical relevance of the findings. The findings are presented in the Summary of Findings table (Table 1). A detailed explanation of quality assessment is available in the eSupplement 4.

\section{RESULTS}

\section{Results of Search}

We retrieved and screened 14,248 titles and abstracts. Full texts of 711 records were assessed and 152 empirical studies met inclusion criteria. We identified 66 relevant non-empirical theoretical works discussing theories and perspectives on compassion (eSupplement 5), and 31 literature reviews (eSupplement 6) (Fig. 2). The development of this literature over time can be seen in Fig. 3, indicating a steady increase in empirical studies that has not been reflected in non-empirical theoretical works nor reviews. 


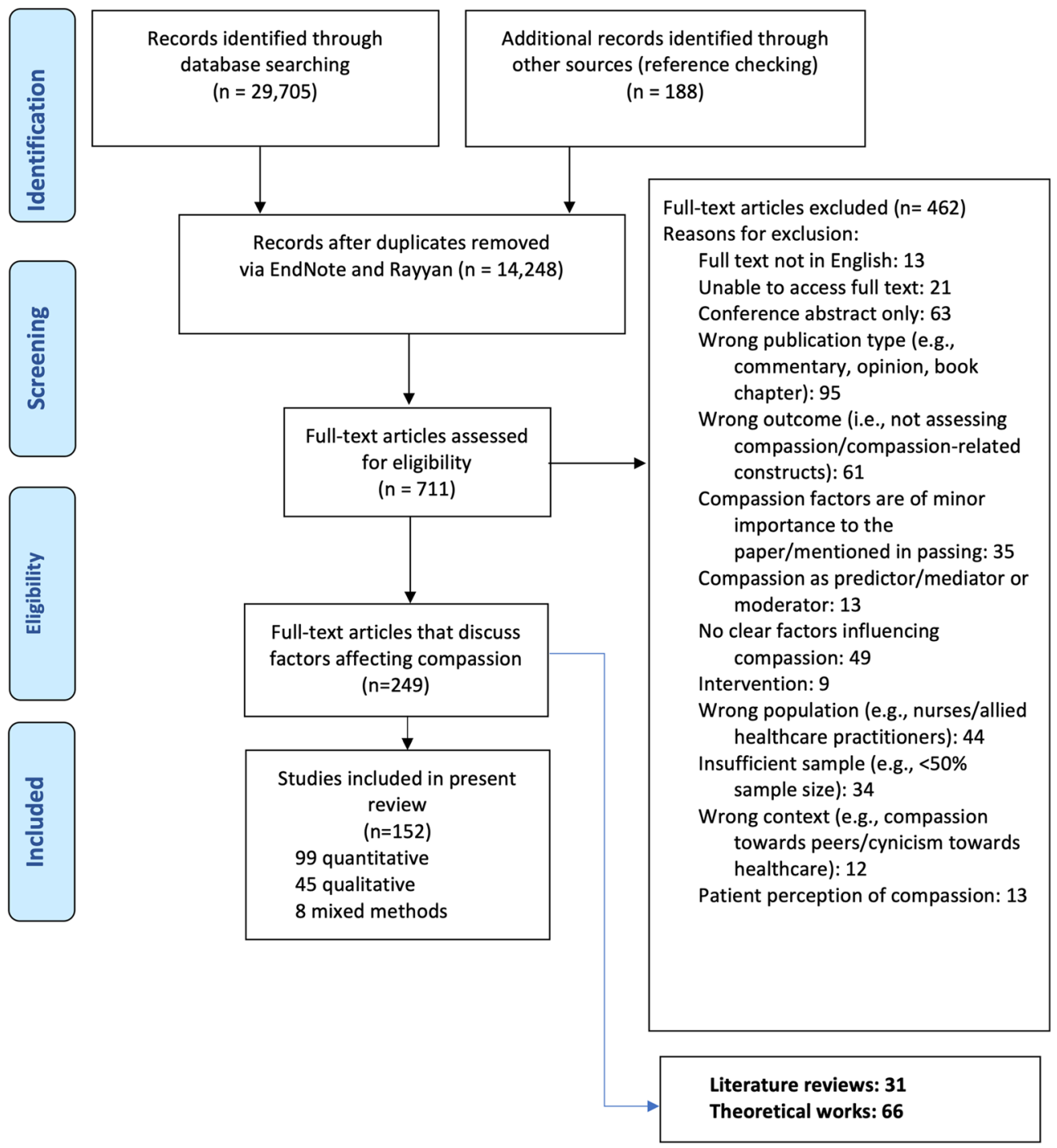

Figure 2 PRISMA 2009 flow diagram

\section{Study and Participant Characteristics}

Table 2 summarizes the characteristics of the included empirical studies. Approximately two-third were quantitative, mostly analytical cross-sectional correlation/association studies relying on self-report. One-third were qualitative, mostly reliant on thematic analysis and, to a lesser extent, reflective writing and focus group designs. Four-fifth of the included studies researched empathy, mostly quantitatively. Only slightly more than one-tenth of included studies assessed compassion or compassionate care, mostly qualitatively. A methodological portrait of the included studies is presented in eSupplement 7. Scales used to quantitatively assess ECRC are presented in eSupplement 8.

More than half of the studies were multi-center studies originating from $30+$ countries worldwide, although research originating in the USA was the most common (eSupplement 9). In total, included studies encompassed 74,866 physicians. Median sample size in quantitative studies was 83 physicians; in qualitative studies, 17 physicians. Of $85 \%$ of studies reporting gender, $48.9 \%$ were females. No studies reported data from non-binary participants. Of $17 \%$ of studies reporting on ethnicity, $70.2 \%$ of physicians were White. Nearly half of empirical studies were solely focused on physicians and onefourth on residents. Three-fifth of the studies focused on physicians of mixed specialties, followed by specific studies of family medicine, oncology, pediatrics, psychiatry and mental health, and internal medicine. A detailed portrait of participants and settings is available in eSupplement 10 .

\section{Risk of Bias of Included Studies}

The methodologic quality of studies is detailed in the Supplement (eSupplements 11, 12). Approximately $60 \%$ of all included studies had serious risk of bias or above. The most common source of bias among quantitative studies was confounding bias, followed by selective reporting, selection of participants, and measurement of outcomes bias. The most 


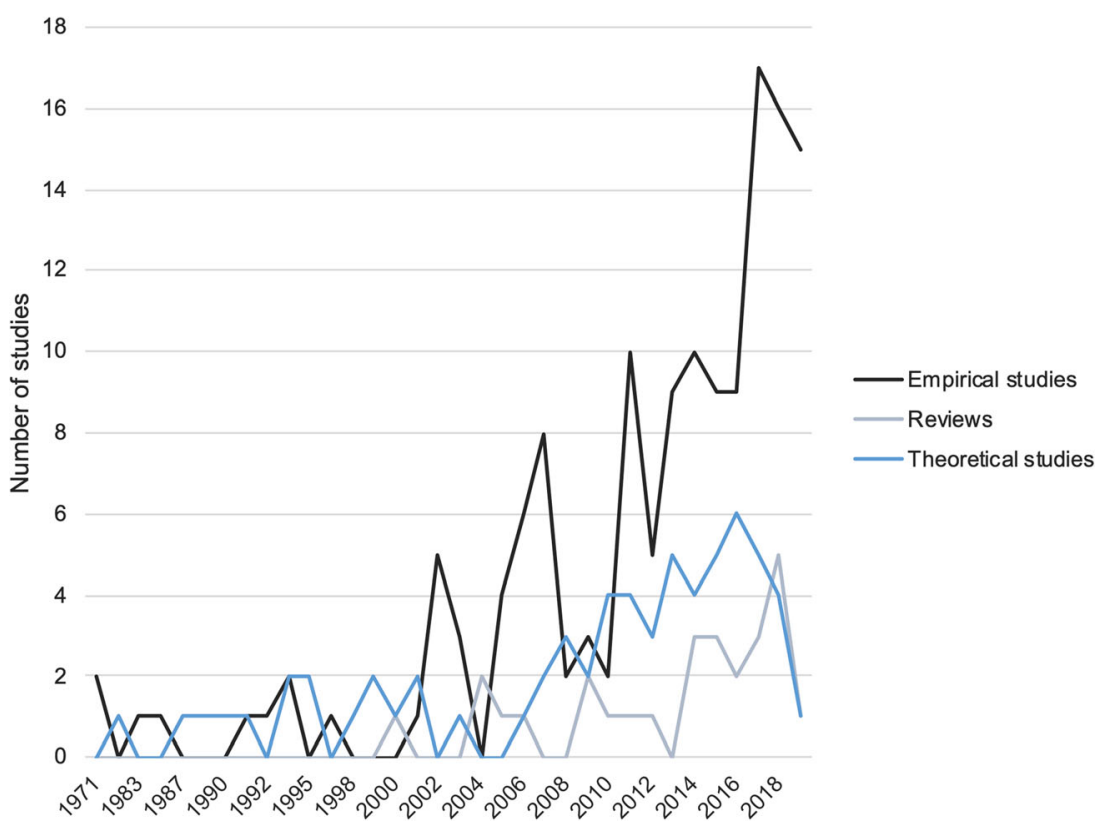

Figure 3 Studies describing the predictors of ECRC over time (1970-2019). The last year of analysis is 2019 because it is the last full year during which the studies were collected (data collection date 24.04.2020).

common sources of bias in qualitative studies were lack of consideration of the relationship between researcher and the participants and insufficient rigor in analysis.

\section{Summary of Evidence According to TMPC Domains}

Physician Factors. Physician factors were included in $88 \%$ of studies, most of which were quantitative.

The top five physician factors with either positive or negative associations to ECRC are presented in Figure 4 A. Of these, professional factors were the most researched: clinical experience tended to predict greater $\mathrm{ECRC}^{38-48}$, although numerous studies also reported no effect ${ }^{49-61}$; it was unclear whether ECRC increases or decreases across residency ${ }^{45,48,62-}$ 77. Studies that featured professional status/seniority mostly showed no effect ${ }^{39,50,53,61,78-82}$, with a smaller number of studies noting positive association ${ }^{71,83-86}$. Small number of studies indicated that greater professional training ${ }^{80,87,88}$ and competency ${ }^{38,41,85}$ positively associated with ECRC. Reporting engagement in extra-professional activities (e.g., teaching, not working at only one place) predicted higher ECRC $^{50,51,56,86,89,90}$. Past medical errors did not show an association $^{91}$. Patient-centered/relational specialities tended to suggest more empathetic physicians than technology-oriented ${ }^{42,64,92,93}$ or surgical specialties ${ }^{60,71,94-98}$. However, the overall evidence regarding the importance of specialty was mixed and inconclusive $e^{45,46,50,54,61,71,72,78,79,81,83,94-96,99-112}$.

Second to professional characteristics, a high proportion of mostly quantitative studies examined socio-demographic factors. Female gender was associated with higher ECRC in numerous studies $41,43,45,47,49,52,55,58,61,64,81-$
$83,92,94,95,99,101,103,108,113-117$ but a comparable number showed no gender effect ${ }^{39,48,50,51,54,60,72,74,76-}$ $80,84,86,96,105,106,116,118-121$; three studies reported males as more compassionate ${ }^{53,111,112}$. Evidence regarding age was s imilarly confli cte d ${ }^{39-41,43,47,49-}$ $51,54,55,58,60,72,77,80,82,84,86,95,99,106,108,120-124$. The evidence in relation to a link between physician ethnicity and ECRC was of limited coherence or of no effect ${ }^{50,58,72,99,108,112,121}$. The presence of cross-cultural differences predicted lower ECRC $^{55,94}$ and the association of ECRC with cultural beliefs and cultural knowledge was observed ${ }^{50,125-127}$. Personal illness experience ${ }^{45,78,128-132}$, experience with illness among relatives or one's own children ${ }^{45,113,132-134}$, or caregiving experiences ${ }^{45,113,131,135}$ predicted greater ECRC. Finally, a small number of predominantly qualitative studies showed spirituality ${ }^{89,136}$, meaning ${ }^{136}$, and religiosity ${ }^{137}$ to predict greater ECRC, although there was no effect of religion ${ }^{39}$. The evidence regarding factors such as living situation $^{39,42,72,82}$, upbringing $98,113,131$, siblings ${ }^{64,76}$, having chil$\operatorname{dren}^{39,41,49,64,77,111-113,138,139}$, the number of children $^{72,82,84,140}$, and marital status ${ }^{43,47,49,50,63,64,72,76,77,83,84,86}$ was conflicted and, hence, inconclusive.

In terms of dispositional factors, pro-social traits/ dispositional compassion (e.g., empathy, compassion, altruism, humanism) ${ }^{47,52,70,73,89,93,116,141,142}$ and the ability to recognize and deal with emotions ${ }^{38,70,76,82,106,116,131,143,144}$ predicted greater ECRC, whereas higher emotionality (both positive and negative $)^{93}$ and idealism predicted lower ECRC ${ }^{145}$. The individual constructs underlying this evidence, however, were scattered and highly heterogeneous with more than 30 personality traits examined. Greater coherence was evident in 
(A) Physician (88\%*)

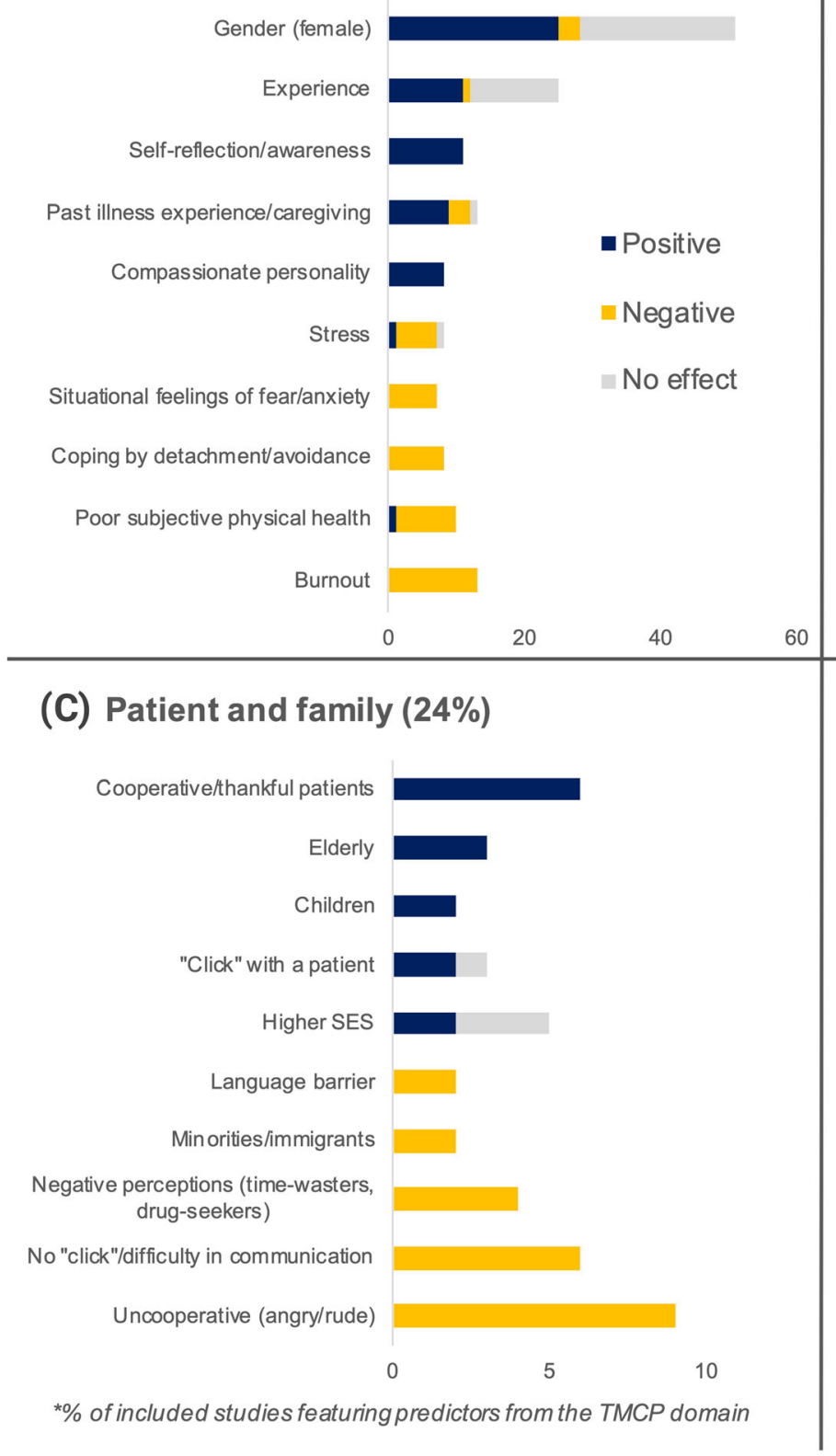

\section{(B) Environmental/organisational (38\%)}

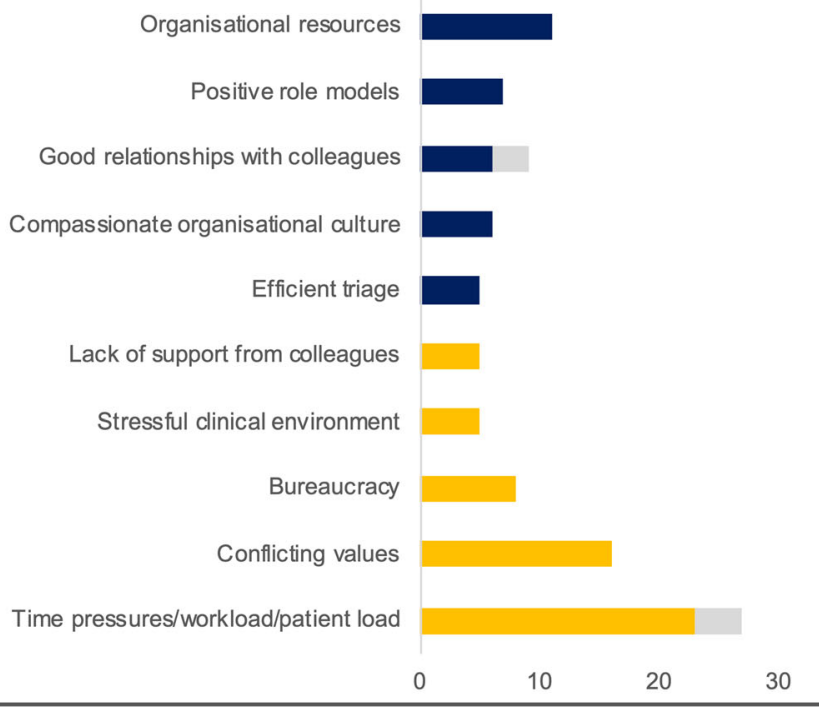

(D) Clinical (15\%)

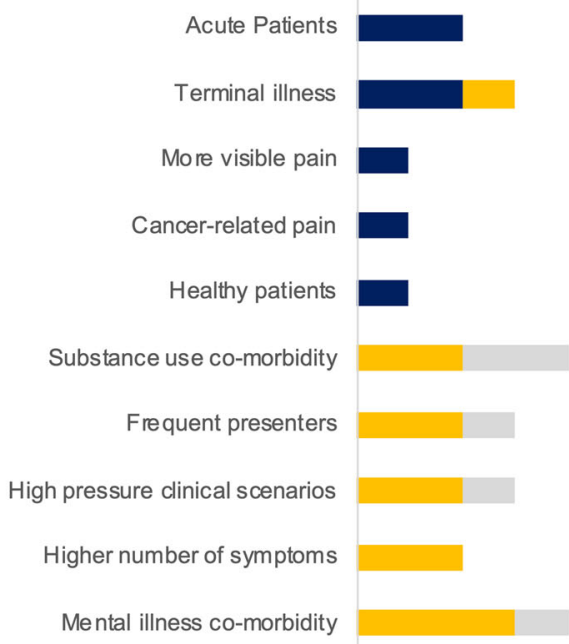

Figure 4 Five most common positive and negative predictors of ECRC for four domains within the Transactional Model. The scale represents the number of quantitative and qualitative studies featuring a particular factor. The number totals to the sum of articles that showed positive or negative factor associations with ECRC (qualitative direct quote, or quantitative significant effect of $\boldsymbol{P}<0.05$ ) or showed no effect (qualitative direct quote or $\mathbf{P}>\mathbf{0 . 0 5}$ ). Top five positive predictors are based on the highest number of studies where the factor showed a positive association. Top negative predictors are based on the highest number of studies where the factor showed a negative association. (A) Physician-related factors $(N=133 / 152),(B)$ environmental/organizational factors $(N=57 / 152)$, (C) patient and family-related factors $(N=37 / 152)$, and $(D)$ clinical factors $(N=23 / 152)$. The detailed portrait of studies with references is available in Table 2.

studies of attitudes and values; positive judgment or nonjudgment ${ }^{98,138}$ and respect ${ }^{87,89}$ predicted greater ECRC, while prejudice and negative judgment predicted lower ECRC $^{80,98,146}$. Having empathy and compassion as a value predicted greater ECRC ${ }^{98,131,147}$.

Positive beliefs about the importance of ECRC in medical care $^{38,50,87,89,90,131,147}$ and the motivation to maintain good standards of care $89,90,148,149$ and to obtain higher job satisfaction by practicing compassion ${ }^{89,131,136,148}$ predicted greater
ECRC. On the contrary, beliefs that ECRC negatively affects objectivity $^{98,107,147,150}$ predicted lower ECRC. In terms of emotional processes, ECRC was also negatively linked to fear of overidentification $^{38,138,149}$, feelings of uncertainty and anxiety $^{151,152}$, and feelings of isolation ${ }^{136,145}$. Positive coping, specifically reflective practices ${ }^{87,89,90,98,100,132,152,153}$, selfawareness $^{87,98,131,143,154}$, and mindfulness ${ }^{75,148}$ predicted greater ECRC, whereas self-doubt and self-criticism ${ }^{147,155}$ predicted lower ECRC, as did avoidance, detachment, and 
hiding emotions $38,100,107,132,138,149,154,156,157$. Studies related to self-compassion showed no effect ${ }^{75,158}$.

Finally, satisfaction with social and intellectual aspects of work and work-life balance ${ }^{50-52,87,89,90,93,155}$ predicted greater ECRC, and so did good personal relationships and social support $76,90,149$, engagement in leisure activities $^{89,111,131,136,153}$, and self-care ${ }^{136,155}$. Conversely, personal problems predicted lower ECRC ${ }^{87,131,146,148}$. Good subjective health predicted greater $\mathrm{ECRC}^{87,107,131}$, while signs of fatigue $^{38,87,93,145,146,149,153,159}$, burnout $^{65,84,93,124,147,148,158,160-}$ ${ }^{166}$, and stress ${ }^{98,131,148,158,160,167}$ tended to associated with ECRC negatively. The evidence regarding the effects of compassion fatigue on $\mathrm{ECRC}^{52,65,154}$ or evidence related to mental health (i.e., mental well-being and anxiety) in relation to ECRC $^{50,77}$ or was too scarce and/or unclear.

Environmental Factors. The second largest domain was related to environmental factors; present in $38 \%$ of included studies. Top five environmental factors with positive and negative associations to ECRC are presented in Figure 4 B. Aspects of the work environment subjectively associated with lower ECRC included time constraints $38,57,65,98,127,131,145,146,148,153-$ 155,157,159,167-170 , bureaucracy ${ }^{38,127,145,146,148,149,153,169-171}$, and stressful clinical environments (e.g., busyness, interruptions) $87,93,138,146,148,149,167$. Lack of continuity had mixed effects ${ }^{123,167,168,172}$. Organizational practices such as good triage or understanding of interruptions timing had a positive effect on $\mathrm{ECRC}^{87,138,149,152}$. The evidence regarding the amount of work (e.g., workload, patient load, long working hours $)^{38,59,61,82,84,93,98,102,127,145-147,149,153,157,163,167}$ and remuneration $^{50,51,85,145,149}$ was mixed.

Qualitative studies suggested that continuous education and counselling $^{56,89,149,153,160,170}$, good leadership ${ }^{136,155,170}$, human resources (e.g., in-house pain and palliative care teams, social workers) ${ }^{89,168}$, and physical resources (e.g., office systems, access to healthy food, and fitness facilities) ${ }^{89}$ were facilitators of ECRC.

Supportive organizational cultures ${ }^{136,153-155,170}$ with positive role models $90,98,136,153,155,160,170$ and supportive colleagues $^{51,89,90,149,153,154}$ were experienced as encouraging ECRC, while experiencing a lack of support ${ }^{57,136,145,148}$ or working with superiors who are unprofessional ${ }^{145,170}$ was seen as interfering. Efficiency-driven ${ }^{136,145,168,169,171}$, disease-centered $^{38,145,149,153,156}$, evidence- or guideline-based healthcare ${ }^{38,87,149,151,171}$ with an emphasis on business $^{38,127,148}$ was reported to interfere with ECRC. Of particular relevance to junior doctors, hidden curriculum in clinical settings (e.g., language, avoiding talking to patients to minimize tasks or obligations) ${ }^{65,98,148}$, and emphasizing intelligence and excellence values among the providers ${ }^{38,127}$ were seen as non-conducive to ECRC. Hierarchical environments reduced $\mathrm{ECRC}^{145,153}$, although the evidence base in this regard is small. Little impact on ECRC was noted from broader healthcare settings (e.g., hospital versus ambulatory settings ${ }^{41,46,79,99}$, urban versus rural $^{47,51,107,124}$, public or private hospitals ${ }^{47,50,55,107}$, working in correctional settings ${ }^{109}$ ).

Patient and Family Factors. Twenty-four percent of studies featured patient and family factors. Top five patient and family factors with positive and negative associations to ECRC are presented in Figure $4 \mathrm{C}$. Cooperative or thankful patients ${ }^{93,121,138,159,167}$ were seen as more likely to receive compassionate care, while uncooperative patients with behaviors seen as problematic (e.g., anger, aggression, entitlement) $38,87,102,138,147,149,159$ and patients who crossed moral boundaries (i.e., drug dealers, sexual abusers) ${ }^{87,149}$, or patients who lack understanding or struggle to communicate com $^{38,121,149,173}$ were seen as less likely. In contrast, a personal "click" and easy and open communication appeared to facilitate ECRC $^{38,87,121,131,146,149,159,167,174}$. Limited studies regarding patients' preferences $^{61}$, self-efficacy ${ }^{61}$, level of sadness ${ }^{175}$, and level of distress ${ }^{176}$ showed no effect on ECRC. Physicians' negative perceptions of patient's motives (e.g., "time wasters," "drug seekers," "attention seekers") ${ }^{138,177}$, and personality (e.g., egoistic, manipulative) $)^{38,102,108,138}$, however, were likely to undermine ECRC.

Demographically, evidence suggested both the possibility that ECRC might be greater toward patients with greater income/education ${ }^{101,138,178}$ or, conversely, to more vulnerable populations (impoverished, elderly, children) $)^{38,61,138,179}$. ECRC toward minorities (i.e., immigrants, people with a language barrier, "enemy" patients during military conflicts) tended to be lower ${ }^{38,40,112,159,174,180}$. Blacks/African Americans were less likely recipients of ECRC as compared to Whites 112,121,181. Gender 61,101,176,178,179,181, age 101,121,176,178,181 (except for elderly $^{38,61}$ and children $^{38,138}$ ), and marital status ${ }^{179}$ of the patients showed no associations with ECRC. Evidence regarding (perceived) doctor-patient similarity was conflicted, with some studies showing that greater patient (or patients' illness) similarity to the physician or their relatives ${ }^{38,117,126,178}$ might predict greater ECRC and others suggesting that similarity to self or relatives might have a negative effect on ECRC due to countertransference ${ }^{93,154}$; there was little evidence for effects associated with patient-doctor age or ethnicity concordance ${ }^{121}$. Results in relation to gender concordance effect were mixed $^{101,117,121,178}$. There were two studies on how factors associated with patients' families might impact patient care showing that appreciative families are likely to receive better ECRC than intrusive/interrogative ${ }^{138}$ and that the closeness of family to the patient had no effect ${ }^{95}$. There were also few studies examining situational factors. Dealing with timeconsuming emotional issues during the diagnosis conversation $^{176,181-183}$ has shown to affect ECRC negatively. Other factors such as presence of empathic opportunities ${ }^{184,185}$, the presence of a third person ${ }^{61}$, and time spent speaking to patients' family ${ }^{95}$ were of mostly of lower quality and inconsistent. 
Clinical Factors. Only 15\% of included studies researched clinical factors. Top five clinical factors with positive and negative associations to ECRC are presented in Figure 4 D. Two studies suggested that patients with acute presentations ${ }^{138,168}$ were more likely to receive ECRC than non-acute patients (or patients whose condition is improving), although more severe conditions ${ }^{61}$ and high-pressure lifethreatening medical scenarios ${ }^{38}$ also made ECRC less likely.

Higher number of symptoms/concerns per presentation $^{61,102}$ and psychosomatic symptoms ${ }^{102,186}$ were negative predictors of ECRC. There were also three studies that showed that patients who have intellectual disabilities ${ }^{38}$, patients with a personality disorder ${ }^{149}$, and greater symptoms of depression ${ }^{173}$ were less likely to receive ECRC, although mental health self-reported status ${ }^{61,101,178}$ had no effect on ECRC. Evidence related to the frequency of presentation was limited to three studies, two of which showed that the frequency of presentation predicts lower ECRC ${ }^{102,138}$, and one study showing no effect ${ }^{61}$. With regard to pain, having or not having pain in general showed no effect on ECRC ${ }^{101,178}$, while in the presence of pain, pain visibility ${ }^{44}$ and pain related to cancer ${ }^{187}$ predicted greater ECRC. Other evidence regarding illness type was based on single studies and was of limited coherence and $\mathrm{r}$ e $\mathrm{p} \mathrm{r}$ e s e n t e d b y s i n g l e s t u d ies $^{38,46,101,128,138,152,154,168,178,182,188,189}$. The evidence related to substance use co-morbidity association with ECRC was inconclusive ${ }^{101,102,176,178}$.

\section{DISCUSSION}

This synthesis identified more than 500 unique predictors of ECRC across 18 subdomains indicating the spread and limited coherence of the research. Consistent with the assertions of recent commentaries ${ }^{190}$, most studies examined physicianrelated predictors while studies testing whether environmental, patient-related, and clinical domains predicted ECRC were less common. In other words, research on the factors predicting ECRC remains practitioner-centric, despite the fact that non-empirical theoretical works ${ }^{191-194}$ and reviews ${ }^{28,195,196}$ suggest that the origins of care are multi-factorial and extend beyond the physician. Most work is concentrated on factors that are largely immutable (e.g., gender, personality, specialty), and therefore less amenable to intervention.

Secondly, our review highlights ongoing inconsistency in the direction of the association between predictors and ECRC. While some factors showed good directional consistency (e.g., positive association of ECRC with self-reflection, negative association of ECRC with red tape), directionality for other factors varied (e.g., patient-doctor similarity, experience, gender). Although it is unknown, this pattern suggests that variations in measurement may matter and/or that unknown moderators are at play. Finally, other than in studies of physician factors, research is predominantly qualitative. While such designs provide rich data in new research arenas, data can be highly context-dependent and difficult to generalize ${ }^{197}$; quantitative research in these domains is clearly needed. Equally, however, qualitative studies may be of use in areas where the constructs are broad (e.g., self-care) or where the links to ECRC are inconsistent.

\section{Confidence in the Findings}

Only $10 \%$ of findings were considered of high confidence and $20 \%$ of moderate confidence (See eSupplement 13 for GRADE-CERQual assessment). The remainder were of low or very low confidence, making it difficult to confidently draw conclusions regarding the predictors of ECRC. Data adequacy (scattered evidence and too few studies to draw conclusions) was a primary issue, and a lack of coherence (using different measurements to measure similar phenomena), and methodological limitations (eSupplements 11,12) were similarly common. Notably, although we paid close attention to the relevance of the studies to compassion (and of compassion) in particular, the strength and direction of evidence was comparable across constructs and in diverse populations, suggesting a similar use and understanding for a broad range of ECRCs (eSupplements 8, 9, 10).

This review should be considered within the context of some limitations. First, the review was only focused on qualified physicians, and reviews among other healthcare professionals (e.g., nursing, allied healthcare, dental care, pharmacy) and student populations are needed. Second, some common empathy measures (e.g., JSPE, IRI) may be subject to face validity issues as indices of compassion. Third, we limited our studies to English only. We excluded only 13 non-English studies, which is a relatively small number, compared to those we included. Lastly, because identifying specific interventional components can be difficult, we excluded studies involving interventions (eSupplement 14). Intervention studies targeting physicians represented approximately $3 \%$ of the initial search. Interventional trial data would allow identification of promising strategies to improve compassion. The results of this systematic review will be helpful in developing interventions targeting factors that are reliably (and mutably) associated with care.

\section{Conclusions and Implications for Research and Practice}

To our knowledge, this report is the first systematic review to identify, classify, and assess consistency, directionality, and study quality for works evaluating the predictors of ECRC in healthcare. Most studies remain concentrated on physician factors with few of patient, clinical, or environmental influences on care. Given that many physician factors may not be suited to intervention, this is a serious limitation. More broadly and despite growth in research, the available evidence remains scattered. Associations between predictors and outcomes are inconsistent, experimental designs remain lacking, and selfreported outcomes predominate. Additionally, where 
predictors other than physician factors are examined, qualitative designs are near-exclusively used. Although qualitative methods are useful and recommended during early stages of research, the study of ECRCs is ripe for quantitative methods to provide more explanatory power and aid systemic changes and policy work.

These concerns noted, some regularities in the predictors of care offer initial guidance for interventions and the enhancement of ECRC in healthcare. At a systems level, if compassionate care is a priority, healthcare managers need to analyze expenditures to ensure efficient resource use, streamlining procedures, protocols, and reporting and prioritizing investment in physicians' continuous education, counselling, and information technology. Second, organizational leaders need to reflect on the concrete instantiations of compassion in organizational policies and the consequent organizational cultures. Is the working environment hierarchical or collaborative? Is the emphasis on efficiency or compassionate care? Does the organization (implicitly) prioritize certain patients over others? If we are to increase compassion in healthcare, these are the hard questions we must tackle. While ongoing attention to the physician factors that influence care is needed, we must also remember that compassion is a systemic issue in healthcare and that it requires systematic research and thinking to solve it.

Corresponding Author: Alina Pavlova, MSc, MA; Faculty of Medical and Health Sciences, Department of Psychological Medicine, The University of Auckland, Building 507, 3, Auckland, New Zealand (e-mail: alina.pavlova@auckland.ac.nz).

Supplementary Information The online version contains supplementary material available at https://doi.org/10.1007/s11606-02107055-2.

\section{REFERENCES}

1. Strauss C, Taylor BL, Gu J, Kuyken W, Baer R, Jones F, et al. What is compassion and how can we measure it? A review of definitions and measures. Clinical psychology review. 2016;47:15-27.

2. American Medical Association. Principles of medical ethics 2021. Available from: https://www.ama-assn.org/about/publications-newsletters/ama-principles-medical-ethics

3. Steinhausen S, Ommen $\mathbf{O}$, Antoine S-L, Koehler T, Pfaff $\mathbf{H}$ Neugebauer E. Short-and long-term subjective medical treatment outcome of trauma surgery patients: the importance of physician empathy. Patient Prefer Adherence. 2014;8:1239.

4. Rakel D, Barrett B, Zhang Z, Hoeft T, Chewning B, Marchand L, et al. Perception of empathy in the therapeutic encounter: effects on the common cold. Patient Educ Couns. 2011;85(3):390-7.

5. Moss J, Roberts MB, Shea L, Jones CW, Kilgannon H, Edmondson DE, et al. Healthcare provider compassion is associated with lower PTSD symptoms among patients with life-threatening medical emergencies: a prospective cohort study. Intensive Care Med. 2019;45(6):815-22.

6. Irwin KE, Greer JA, Khatib J, Temel JS, Pirl WF. Early palliative care and metastatic non-small cell lung cancer: potential mechanisms of prolonged survival. Chron Respir Dis. 2013;10(1):35-47.
7. Kelley JM, Kraft-Todd G, Schapira L, Kossowsky J, Riess H. The influence of the patient-clinician relationship on healthcare outcomes: a systematic review and meta-analysis of randomized controlled trials. PLoS One. 2014;9(4):e94207.

8. Dorflinger L, Kerns RD, Auerbach SM. Providers' roles in enhancing patients' adherence to pain self management. Transl Behav Med. 2013;3(1):39-46.

9. Post SG. Compassionate care enhancement: benefits and outcomes. Int J Pers Cent Med. 2011;1(4):808-13.

10. Cleary PD. Evolving concepts of patient-centered care and the assessment of patient care experiences: optimism and opposition. $\mathrm{J}$ Health Polit Policy Law. 2016;41(4):675-96.

11. Neumann M, Wirtz M, Bollschweiler E, Mercer SW, Warm M, Wolf $\mathbf{J}$, et al. Determinants and patient-reported long-term outcomes of physician empathy in oncology: a structural equation modelling approach. Patient Educ Couns. 2007;69(1-3):63-75.

12. Sinclair S, Norris JM, McConnell SJ, Chochinov HM, Hack TF, Hagen NA, et al. Compassion: a scoping review of the healthcare literature. BMC Palliat Care. 2016;15(1):1-16.

13. Post SG, Ng LE, Fischel JE, Bennett M, Bily L, Chandran L, et al. Routine, empathic and compassionate patient care: definitions, development, obstacles, education and beneficiaries. J Eval Clin Pract. 2014;20(6):872-80.

14. Stewart-Brown S. Emotional wellbeing and its relation to health: physical disease may well result from emotional distress. BMJ. 1998;317(7173): 1608-9.

15. Wiseman $\mathbf{P}$, Watson $\mathbf{N}$. "Because I've got a learning disability, they don't take me seriously:" violence, wellbeing, and devaluing people with learning disabilities. J Interpers Violence. 2021.

16. McManus I, Livingston G, Katona C. The attractions of medicine: the generic motivations of medical school applicants in relation to demography, personality and achievement. BMC Med Educ. 2006;6(1):1-15.

17. Vaglum P, Wiers-Fenssen F, Ekeberg $\emptyset$. Motivation for medical school: the relationship to gender and specialty preferences in a nationwide sample. Med Educ. 1999 Apr;33(4): 236-42.

18. Glasberg A-L, Eriksson S, Norberg A. Burnout and 'stress of conscience'among healthcare personnel. J Adv Nurs. 2007;57(4):392-403.

19. Beckett K. Professional wellbeing and caring: exploring a complex relationship. Br J Nurs. 2013;22(19):1118-24.

20. Dasan S, Gohil P, Cornelius V, Taylor C. Prevalence, causes and consequences of compassion satisfaction and compassion fatigue in emergency care: a mixed-methods study of UK NHS Consultants. Emerg Med J. 2015;32(8):588-94.

21. Lown BA, Rosen J, Marttila J. An agenda for improving compassionate care: a survey shows about half of patients say such care is missing. Health Aff (Millwood). 2011;30(9):1772-8.

22. Francis R. Report of the Mid Staffordshire NHS Foundation Trust public inquiry: executive summary: The Stationery Office; 2013.

23. Fernando AT, Consedine NS. Beyond compassion fatigue: the transactional model of physician compassion. J Pain Symptom Manage. 2014;48(2):289-98.

24. Barker RL. The social work dictionary. 5 ed. Washington, DC: NASW Press; 2003.

25. Geer JH, Estupinan LA, Manguno-Mire GM. Empathy, social skills, and other relevant cognitive processes in rapists and child molesters. Aggress Violent Behav. 2000;5(1):99-126.

26. Hojat M, Mangione S, Nasca TJ, Cohen MJ, Gonnella JS, Erdmann JB, et al. The Jefferson Scale of Physician Empathy: development and preliminary psychometric data. Educ Psychol Meas. 2001;61(2):349-65.

27. Sinclair S, Kondejewski J, Schulte F, Letourneau N, Kuhn S, RaffinBouchal S, et al. Compassion in Pediatric Healthcare: A Scoping Review. Journal of Pediatric Nursing-Nursing Care of Children \& Families. 2020;51:57-66.

28. Sinclair S, Norris JM, McConnell SJ, Chochinov HM, Hack TF, Hagen NA, et al. Compassion: a scoping review of the healthcare literature. BMC palliative care. 2016;15:6.

29. Liberati A, Altman DG, Tetzlaff J, Mulrow C, Gøtzsche PC, Ioannidis JP, et al. The PRISMA statement for reporting systematic reviews and meta-analyses of studies that evaluate health care interventions: explanation and elaboration. J Clin Epidemiol. 2009;62(10):e1-e34.

30. Ouzzani M, Hammady H, Fedorowicz Z, Elmagarmid A. Rayyan-a web and mobile app for systematic reviews. Systematic Reviews. 2016;5(1): 1-10.

31. Noyes J, Booth A, Cargo M, Flemming K, Harden A, Harris J, et al. Qualitative evidence. In: Higgins JPT, Thomas J, Chandler J, Cumpston 
M, Li T, Page MJ, et al., editors. Cochrane Handbook for systematic reviews of interventions. 6.2 ed: Cochrane; 2019.

32. Fernando AT, Consedine NS. Development and initial psychometric properties of the Barriers to Physician Compassion questionnaire. Postgrad Med J. 2014;90(1065):388-95.

33. Britten N, Campbell R, Pope C, Donovan J, Morgan M, Pill R. Using meta ethnography to synthesise qualitative research: a worked example. J Health Serv Res Policy. 2002;7(4):209-15.

34. Higgins JP, Altman DG, Gøtzsche PC, Jüni P, Moher D, Oxman AD, et al. The Cochrane Collaboration's tool for assessing risk of bias in randomised trials. BMJ. 2011;343.

35. Sterne JAC, Hernán MA, McAleenan A, Higgins JPT, Thomas J, Chandler $\mathbf{J}$. Assessing risk of bias in a non-randomized study. In: Higgins JPT, Thomas J, Chandler J, Cumpston M, Li T, Page MJ, et al., editors. Cochrane Handbook for systematic reviews of interventions. 6.2 ed: Oxford: John Wiley \& Sons, Ltd: Cochrane; 2019.

36. Atkins S, Lewin S, Smith H, Engel M, Fretheim A, Volmink J. Conducting a meta-ethnography of qualitative literature: lessons learnt. BMC Med Res Methodol. 2008;8(1):1-10.

37. Lewin S, Booth A, Glenton C, Munthe-Kaas H, Rashidian A, Wainwright M, et al. Applying GRADE-CERQual to qualitative evidence synthesis findings: introduction to the series. Implementation Science. 2018.

38. Bayne H, Neukrug E, Hays D, Britton B. A comprehensive model for optimizing empathy in person-centered care. Patient Educ Couns. 2013;93(2):209-15.

39. Clara A, Merino J, Mateos E, Ysa A, Roman B, Vidal-Barraquer F, et al. The vascular surgeon facing clinical ethical dilemmas (the VASCUETHICS Study): 'V'-shaped association between compassionate attitudes and professional seniority. Eur J Vasc Endovasc Surg. 2006;31(6):594-9.

40. Handford C, Lemon J, Grimm MC, Vollmer-Conna U. Empathy as a function of clinical exposure - reading emotion in the eyes. PLoS One. 2013;8(6):e65159.

41. Julia-Sanchis R, Richart-Martinez M, Garcia-Aracil N, Jose-Alcaide L, Piquer-Donat T, Castejon-de-la-Encina ME. Measuring the levels of burnout syndrome and empathy of Spanish emergency medical service professionals. Australas Emerg Care. 2019;22(3):193-9.

42. Kataoka HU, Koide N, Hojat M, Gonnella JS. Measurement and correlates of empathy among female Japanese physicians. BMC Med Educ. 2012;12:48.

43. Katsari V, Tyritidou A, Domeyer PR, Giorgi G. Physicians' selfassessed empathy and patients' perceptions of physicians' empathy: validation of the Greek Jefferson scale of patient perception of physician empathy. Biomed Res Int. 2020;2020:9379756

44. Paul-Savoie E, Bourgault P, Potvin S, Gosselin E, Lafrenaye S. The impact of pain invisibility on patient-centered care and empathetic attitude in chronic pain management. Pain Res Manag. 2018;2018:6375713.

45. Roberts LW, Warner TD, Moutier C, Geppert CMA, Green Hammond KA. Are doctors who have been ill more compassionate? Attitudes of resident physicians regarding personal health issues and the expression of compassion in clinical care. Psychosomatics. 2011;52(4):367-74

46. Santamaria-Garcia H, Baez S, Garcia AM, Flichtentrei D, Prats M, Mastandueno R, et al. Empathy for others' suffering and its mediators in mental health professionals. Sci Rep. 2017;7(1):6391.

47. Shariat Sv, Eshtad E, Ansari S. Empathy and its correlates in Iranian physicians: a preliminary psychometric study of the Jefferson Scale of Physician Empathy. Med Teach. 2010;32(10):e417-21.

48. Wolfshohl JA, Keegan Bradley CB, Bell S, Hodges C, Knowles H, Chaudhari BR, et al. Association between empathy and burnout among emergency medicine physicians. J Clin Med Res. 2019;11(7):532.

49. Bratek A, Bulska W, Bonk M, Seweryn M, Krysta K. Empathy among physicians, medical students and candidates. Psychiatr Danub. 2015;27 Suppl 1:S48-52.

50. Carmel S, Glick SM. Compassionate-empathic physicians: personality traits and social-organizational factors that enhance or inhibit this behavior pattern. Soc Sci Med. 1996;43(8):1253-61.

51. Charles JA, Ahnfeldt-Mollerup P, Sondergaard J, Kristensen T. Empathy variation in general practice: a survey among general practitioners in Denmark. Int J Environ Res Public Health. 2018;15(3).

52. Gleichgerrcht E, Decety J. Empathy in clinical practice: how individual dispositions, gender, and experience moderate empathic concern, burnout, and emotional distress in physicians. PLoS One. 2013;8(4):e61526.
53. Jiao Y, Phillips MR, Sheng Y, Wu G, Li X, Xiong W, et al. Crosssectional study of attitudes about suicide among psychiatrists in Shanghai. BMC Psychiatry. 2014;14:87.

54. Kondo K, Fujimori M, Shirai Y, Yamada Y, Ogawa A, Hizawa N, et al. Characteristics associated with empathic behavior in Japanese oncologists. Patient Educ Couns. 2013;93(2):350-3.

55. Kozeny $\mathbf{J}$, Tisanska $\mathbf{L}$. The structure of the Jefferson Scale of Physician Empathy in Czech physicians. Cesk Psychol. 2013;57(6):521-32.

56. Lelorain S, Sultan S, Zenasni F, Catu-Pinault A, Jaury P, Boujut E, et al. Empathic concern and professional characteristics associated with clinical empathy in French general practitioners. Eur J Gen Pract. 2013;19(1):23-8.

57. Lown BA, Shin A, Jones RN. Can organizational leaders sustain compassionate, patient-centered care and mitigate burnout? J Healthc Manag. 2019;64(6):398-412.

58. Pollak KI, Arnold RM, Jeffreys AS, Alexander SC, Olsen MK, Abernethy AP, et al. Oncologist communication about emotion during visits with patients with advanced cancer. J Clin Oncol. 2007;25(36):5748-52.

59. Putrino N, Tabullo Á, Mesurado B, de Minzi MCR. Are there differences in health professionals' empathy due to academic and clinical experience? Curr Psychol. 2018.

60. Walocha E, Tomaszewska IM, Mizia E. Empathy level differences between Polish surgeons and physicians. Folia Med Cracov. 2013;53(1):47-54

61. Zandbelt LC, Smets EMA, Oort FJ, Godfried MH, de Haes HCJM. Patient participation in the medical specialist encounter: does physicians' patient-centred communication matter? Patient Educ Couns. 2007;65(3):396-406.

62. Foreback J, Kusz H, Lepisto BL, Pawlaczyk B. Empathy in internal medicine residents at community-based hospitals: a cross-sectional study. J Med Educ Curric Dev. 2018;5.

63. Hong M, Bahn GH, Lee WH, Moon SJ. Empathy in Korean psychiatric residents. Asia Pac Psychiatry. 2011;3(2):83-90.

64. Park C, Lee YJ, Hong M, Jung C-H, Synn Y, Kwack Y-S, et al. A multicenter study investigating empathy and burnout characteristics in medical residents with various specialties. J Korean Med Sci. 2016;31(4):590-7

65. Rawal S, Strahlendorf C, Nimmon L. Challenging the myth of the attrition of empathy in paediatrics residents. Med Educ. 2020;54(1):827.

66. Bellini LM, Baime M, Shea JA. Variation of mood and empathy during internship. JAMA. 2002;287(23):3143-6.

67. Bellini LM, Shea JA. Mood change and empathy decline persist during three years of internal medicine training. Acad Med. 2005;80(2):164-7.

68. Rosen IM, Gimotty PA, Shea JA, Bellini LM. Evolution of sleep quantity, sleep deprivation, mood disturbances, empathy, and burnout among interns. Acad Med. 2006;81(1):82-5.

69. West CP, Huntington JL, Huschka MM, Novotny PJ, Sloan JA, Kolars JC, et al. A prospective study of the relationship between medical knowledge and professionalism among internal medicine residents. Acad Med. 2007;82(6):587-92.

70. Greenberg L, Agrawal D, Toto R, Blatt B. Empathy, sense of power, and personality: do they change during pediatric residency? South Med J. 2015;108(8):471-4.

71. Khajavi F, Hekmat H. A comparative study of empathy: the effects of psychiatric training. Arch Gen Psychiatry. 1971;25(6):490-3.

72. Lee PT, Loh J, Sng G, Tung J, Yeo KK. Empathy and burnout: a study on residents from a Singapore institution. Singapore Med J. 2018;59(1):50-4.

73. Mangione S, Kane GC, Caruso JW, Gonnella JS, Nasca TJ, Hojat M. Assessment of empathy in different years of internal medicine training. Med Teach. 2002;24(4):370-3.

74. Petrahai SK, Nwangwu JT. A study of empathy in emergency medicine residents at a Connecticut residency program [M.P.H.]. Ann Arbor: Southern Connecticut State University; 2003.

75. Reed S, Kemper KJ, Schwartz A, Batra M, Staples BB, Serwint JR, et al. Variability of burnout and stress measures in pediatric residents: an exploratory single-center study from the pediatric resident burnoutresilience study consortium. J Evid Based Integr Med. 2018;23:2515690X18804779

76. Saguem BN, Bouzaâbia Z, Braham A, Nasr SB. Empathic abilities and their mediators in Tunisian psychiatry trainees. J Ment Health Train Educ Pract. 2020.

77. Shanafelt TD, West C, Zhao X, Novotny P, Kolars J, Habermann T, et al. Relationship between increased personal well-being and enhanced 
empathy among internal medicine residents. J Gen Intern Med. 2005;20(7):559-64.

78. Brady C, Bambury RM, O'Reilly S. Empathy and the wounded healer: a mixed-method study of patients and doctors views on empathy. Ir Med J. 2015; 108(4):125-6.

79. Di Lillo M, Cicchetti A, Lo Scalzo A, Taroni F, Hojat M. The Jefferson Scale of Physician Empathy: preliminary psychometrics and group comparisons in Italian physicians. Acad Med. 2009;84(9):1198-202.

80. Moriarty A, Nearchou F, Byrne M, Cullen W, Hennessy E. General practitioners' training and their attitudes towards young people who self-harm: a cross-sectional survey. Early Interv Psychiatry. 2020.

81. Suh DH, Hong JS, Lee DH, Gonnella JS, Hojat M. The Jefferson Scale of Physician Empathy: a preliminary psychometric study and group comparisons in Korean physicians. Med Teach. 2012;34(6):e464-8.

82. Zenasni F, Boujut E, Buffel du Vaure C, Catu-Pinault A, Tavani JL, Rigal L, et al. Development of a French-language version of the Jefferson Scale of Physician Empathy and association with practice characteristics and burnout in a sample of general practitioners. Int $J$ Pers Cent Med. 2012;2(4):759-66.

83. Cyrus A, Salehi B, Naziri M, Sedeh BS, Vosoulie R. Empathic communication and essential instruction for medical students. J Biol Today's World. 2017;6(6):97-101.

84. Ferreira S, Afonso P, Ramos MDR. Empathy and burnout: a multicentre comparative study between residents and specialists. J Eval Clin Pract. 2020;26(1):216-22.

85. Jing $\mathbf{D}$, Jin $\mathbf{Y}$, Liu $\mathbf{J}$. The impact of monetary incentives on physician prosocial behavior in online medical consulting platforms: evidence from China. JMIR. 2019;21(7):e14685.

86. Osim JH, Essien EA, Okegbe J, Udofia O. The Jefferson scale of physician empathy: a preliminary study of validity and reliability among physicians in Nigerian tertiary hospital. Acta Medica International. 2019;6(1):11-6.

87. Derksen F, Bensing J, Kuiper S, van Meerendonk M, Lagro-Janssen A. Empathy: what does it mean for GPs? A qualitative study. Fam Pract. 2015;32(1):94-100.

88. Pardeshi GS, Kadam D, Chandanwale A, Bollinger R, Deluca A Resident doctors' attitudes toward tuberculosis patients. Indian $J$ Tuberc. 2017;64(2):89-92

89. Chou CM, Kellom K, Shea JA. Attitudes and habits of highly humanistic physicians. Acad Med. 2014;89(9):1252-8.

90. Swendiman RA, Marcaccio CL, Han J, Hoffman DI, Weiner TM, Nance ML, et al. Attitudes and habits of highly humanistic surgeons: a single-institution, mixed-methods study. Acad Med. 2019;94(7):102732

91. West CP, Huschka MM, Novotny PJ, Sloan JA, Kolars JC, Habermann TM, et al. Association of perceived medical errors with resident distress and empathy: a prospective longitudinal study. JAMA. 2006;296(9):1071-8.

92. Hojat M, Gonnella JS, Nasca TJ, Mangione S, Veloksi JJ, Magee M. The Jefferson Scale of Physician Empathy: Further psychometric data and differences by gender and specialty at item level. Acad Med. 2002;77(Suppl10):S58-S60.

93. Picard J, Catu-Pinault A, Boujut E, Botella M, Jaury P, Zenasni F. Burnout, empathy and their relationships: a qualitative study with residents in General Medicine. Psychol Health Med. 2016;21(3):354-61.

94. Alcorta-Garza A, San-Martin M, Delgado-Bolton R, Soler-Gonzalez J, Roig H, Vivanco L. Cross-validation of the Spanish HP-version of the Jefferson scale of empathy confirmed with some cross-cultural differences. Front Psychol. 2016;7.

95. Cicekci F, Duran N, Ayhan B, Arican S, Ilban O, Kara I, et al. The communication between patient relatives and physicians in intensive care units. BMC Anesthesiol. 2017;17(1):97.

96. Hojat M, Gonnella JS, Nasca TJ, Mangione S, Vergare M, Magee $\mathbf{M}$. Physician empathy: definition, components, measurement, and relationship to gender and specialty. Am J Psychiatry. 2002;159(9): 1563-9.

97. Stanton C, Sethi FN, Dale O, Phelan M, Laban JT, Eliahoo J. Comparison of emotional intelligence between psychiatrists and surgeons. Psychiatrist. 2011;35(4):124-9.

98. Stratta EC, Riding DM, Baker P. Ethical erosion in newly qualified doctors: perceptions of empathy decline. Int J Med Educ. 2016;7:28692

99. Chaitoff A, Sun B, Windover A, Bokar D, Featherall J, Rothberg MB, et al. Associations between physician empathy, physician characteristics, and standardized measures of patient experience. Acad Med 2017;92(10):1464-71.
100. Davidsen AS, Fosgerau CF. General practitioners' and psychiatrists' responses to emotional disclosures in patients with depression. Patient Educ Couns. 2014;95(1):61-8.

101. Bertakis KD, Azari R. Determinants and outcomes of patient-centered care. Patient Educ Couns. 2011;85(1):46-52.

102. Sandikci KB, Ustu Y, Sandikci MM, Kayhan Tetik B, Isik D, Ugurlu M. Attitudes and behaviors of physicians in dealing with difficult patients and relatives: a cross-sectional study in two training and research hospitals. Turk J Med Sci. 2017;47(1):222-33.

103. Paasche-Orlow M, Roter D. The communication patterns of internal medicine and family practice physicians. J Am Board Fam Med. 2003;16(6):485-93.

104. McFarland DC, Malone AK, Roth A. Acute empathy decline among resident physician trainees on a hematology-oncology ward: an exploratory analysis of house staff empathy, distress, and patient death exposure. Psychooncology. 2017;26(5):698-703.

105. McFarland DC, Roth A. Resilience of internal medicine house staff and its association with distress and empathy in an oncology setting. Psychooncology. 2017;26(10):1519-25.

106. Jin J, Li H, Song W, Jiang N, Zhao W, Wen D. The mediating role of psychological capital on the relation between distress and empathy of medical residents: a cross-sectional survey. Med Educ Online. 2020;25(1): 1710326 .

107. Mahoney S, Sladek RM, Neild T. A longitudinal study of empathy in pre-clinical and clinical medical students and clinical supervisors. BMC Med Educ. 2016;16(1):270.

108. Psyhojos MA. Aging, empathy, and the Internet of Things: a measure of physician readiness to treat older adults: Massachusetts Institute of Technology; 2017.

109. Dhawan N, Steinbach AB, Halpern J. Physician empathy and compassion for inmate-patients in the correctional health care setting. J Correct Health Care. 2007;13(4):257-67.

110. Gateshill G, Kucharska-Pietura K, Wattis J. Attitudes towards mental disorders and emotional empathy in mental health and other healthcare professionals. Psychiatrist. 2011;35(3):101-5.

111. Moralle MR, Preston JS, Chen L, Berberian WS. An exploratory study of empathy in resident physicians at an urban medical center. Int $J$ Caring Sci. 2016;9(2):526-33

112. Foo PK, Frankel RM, McGuire TG, Zaslavsky AM, Elston Lafata $\mathbf{J}$, Ming T-S. Patient and physician race and the allocation of time and patient engagement efforts to mental health discussions in primary care: an observational study of audiorecorded periodic health examinations. J Ambul Care Manage. 2017;40(3):246-56.

113. Bateman LB, White ML, Tofil NM, Clair JM, Needham BL. A qualitative examination of physician gender and parental status in pediatric end-of-life communication. Health Commun. 2017;32(7):9039.

114. Bylund CL, Makoul G. Empathic communication and gender in the physician-patient encounter. Patient Educ Couns. 2002;48(3):207-16.

115. Dehning S, Reis E, Krause D, Gasperi S, Meyer S, Dargel S, et al Empathy in high-tech and high-touch medicine. Patient Educ Couns. 2014;95(2):259-64.

116. Kliszcz J, Nowicka-Sauer $\mathbf{K}$, Trzeciak B, Nowak P, Sadowska A Empathy in health care providers-validation study of the Polish version of the Jefferson Scale of Empathy. Adv Med Sci. 2006;51:219-25.

117. Wasserman RC, Inui TS, Barriatua RD, Carter WB, Lippincott P. Responsiveness to maternal concern in preventive child health visits: an analysis of clinician-parent interactions. J Dev Behav Pediatr. 1983;4(3):171-6.

118. Borracci RA, Doval HC, Nunez C, Samarelli M, Tamini S, Tanus E. Measurement of empathy among Argentine cardiologists: Psychometrics and differences by age, gender, and subspecialty. Cardiol $\mathrm{J}$. 2015;22(1):52-6.

119. Kobayasi R, Tempski PZ, Arantes-Costa FM, Martins MA. Gender differences in the perception of quality of life during internal medicine training: a qualitative and quantitative analysis. BMC Med Educ. 2018; 18(1):281

120. Silvester J, Patterson F, Koczwara A, Ferguson E. "Trust me...": psychological and behavioral predictors of perceived physician empathy. J Appl Psychol. 2007;92(2):519-27.

121. Street Jr RL, Gordon H, Haidet P. Physicians' communication and perceptions of patients: is it how they look, how they talk, or is it just the doctor? Soc Sci Med. 2007;65(3):586-98.

122. Avasarala SK, Whitehouse S, Drake SM. Internship and empathy: variations across time and specialties. South Med J. 2015;108(10):5915. 
123. Komisar J, McFarland DC. Is empathy associated with a self-ascribed sense of meaning among resident physicians working with patients nearing the end of life on a hematology-oncology ward? Psychooncology. 2017;26(9): 1403-6.

124. Yuguero O, Ramon Marsal J, Esquerda M, Vivanco L, Soler-Gonzalez J. Association between low empathy and high burnout among primary care physicians and nurses in Lleida, Spain. Eur $J$ Gen Pract. 2017;23(1):4-10.

125. Epstein RM, Borrell i Carrio F. Pudor, honor, and autoridad: the evolving patient-physician relationship in Spain. Patient Educ Couns. 2001;45(1):51-7.

126. Kirmayer LJ. Empathy and alterity in cultural psychiatry. Ethos. 2008;36(4):457-74

127. Haider SI, Riaz Q, Gill RC. Empathy in clinical practice: a qualitative study of early medical practitioners and educators. J Pak Med Assoc. 2020;70(1): 116-22

128. Fox FE, Rodham KJ, Harris MF, Taylor GJ, Sutton J, Scott J, et al. Experiencing "the other side": a study of empathy and empowerment in general practitioners who have been patients. Qual Health Res. 2009;19(11): 1580-8.

129. Jaye C, Wilson $\mathbf{H}$. When general practitioners become patients. Health (London). 2003;7(2):201-25.

130. Pensek L, Selic P. Empathy and burnout in Slovenian family medicine doctors: the first presentation of Jefferson scale of empathy results. $\mathrm{Zdr}$ Varst. 2018;57(3):155-65.

131. Uygur J, Brown JB, Herbert C. Understanding compassion in family medicine: a qualitative study. Br J Gen Pract. 2019;69(680):e208-e16.

132. Woolf K, Cave J, McManus IC, Dacre JE. 'It gives you an understanding you can't get from any book.' The relationship between medical students' and doctors' personal illness experiences and their performance: a qualitative and quantitative study. BMC Med Educ. 2007;7:50.

133. Batton B, Verhulst S, Batton D, Davis A, Collin M, Walsh M. Perspectives of physician parents in the NICU. Child Health Care. 2011;40(4):326-43.

134. Krenek RJ, Zalewski C. Psychiatric illness in families of mental health professionals: relationship to career choice and self-perceived therapeutic variables. J Soc Behav Pers. 1993;8(3):439-52.

135. Wohlgemuth CM, Auerbach HP, Parker VA. Advantages and challenges: the experience of geriatrics health care providers as family caregivers. Gerontologist. 2015;55(4):595-604.

136. Anandarajah G, Roseman JL. A qualitative study of physicians' views on compassionate patient care and spirituality: medicine as a spiritual practice? R I Med J (2013). 2014;97(3):17-22.

137. Pawlikowski J, Sak JJ, Marczewski K. Physicians' religiosity and attitudes towards patients. Ann Agric Environ Med. 2012;19(3):503-7.

138. Batley NJ, Nasreddine Z, Chami A, Zebian D, Bachir R, Abbas HA. Cynicism and other attitudes towards patients in an emergency department in a middle eastern tertiary care center. BMC Med Educ. 2016;16:36.

139. Gottenborg E, Maw A, Ngov LK, Burden M, Ponomaryova A, Jones CD. You can't have it all: the experience of academic hospitalists during pregnancy, parental leave, and return to work. J Hosp Med. 2018;13(12):836-9

140. Fulop E, Devecsery A, Hausz K, Kovacs Z, Csabai M. Relationship between empathy and burnout among psychiatric residents. New Medicine. 2011;2011(4):143-7.

141. Hojat M, Mangione S, Nasca TJ, Gonnella JS, Magee M. Empathy scores in medical school and ratings of empathic behavior in residency training 3 years later. J Soc Psychol. 2005; 145(6):663-72.

142. Aomatsu M, Otani T, Tanaka A, Ban N, van Dalen J. Medical students' and residents' conceptual structure of empathy: a qualitative study. Educ Health (Abingdon). 2013;26(1):4-8.

143. Muslin HL, Schlessinger N. Toward the teaching and learning of empathy. Bull Menninger Clin. 1971;35(4):262-71.

144. Scott E. A positively embodied approach to psychotherapy. Women Ther. 2019;42(1-2): 131-46.

145. Peng J, Clarkin C, Doja A. Uncovering cynicism in medical training: a qualitative analysis of medical online discussion forums. BMJ Open. 2018;8(10):e022883.

146. Derksen FAWM, Olde Hartman T, Bensing J, Lagro-Janssen A. Empathy in general practice-the gap between wishes and reality: comparing the views of patients and physicians. Fam Pract. 2018;35(2):203-8.

147. Lyness Richard DA. Physicians' use of empathy in response to patients' emotional concerns. Diss Abstr Int. 1993;54(2-A):463-4.
148. Branch WT, Jr., Weil AB, Gilligan MC, Litzelman DK, Hafler JP, Plews-Ogan M, et al. How physicians draw satisfaction and overcome barriers in their practices: "It sustains me". Patient Educ Couns. 2017;100(12):2320-30.

149. Derksen FA, Olde Hartman TC, Bensing JM, Lagro-Janssen AL. Managing barriers to empathy in the clinical encounter: a qualitative interview study with GPs. Br J Gen Pract. 2016;66(653):e887-e95.

150. Ross R. "This will only hurt a bit" evaluating the usage of patient focused empathy amongst general surgery residents [Psy.D.]. Ann Arbor: Rutgers The State University of New Jersey, Graduate School of Applied and Professional Psychology; 2017.

151. Baker LR, Martimianakis MAT, Nasirzadeh Y, Northup E, Gold K, Friesen F, et al. Compassionate care in the age of evidence-based practice: a critical discourse analysis in the context of chronic pain care. Acad Med. 2018;93(12):1841-9.

152. Pinder R. Striking balances: detachment or empathy in the management of Parkinson's disease? Fam Pract. 1992;9(3):274-8.

153. Ahrweiler F, Neumann M, Goldblatt H, Hahn EG, Scheffer C. Determinants of physician empathy during medical education: hypothetical conclusions from an exploratory qualitative survey of practicing physicians. BMC Med Educ. 2014;14:122.

154. Bessen S, Jain RH, Brooks WB, Mishra M. "Sharing in hopes and worries"-a qualitative analysis of the delivery of compassionate care in palliative care and oncology at end of life. Int J Qual Stud Health Wellbeing. 2019;14(1):1622355.

155. Mills J, Wand T, Fraser JA. Exploring the meaning and practice of selfcare among palliative care nurses and doctors: A qualitative study. BMC Palliat Care. 2018;17(1):63.

156. Crowe S, Brugha R. "We've all had patients who've died ...": narratives of emotion and ideals of competence among junior doctors. Soc Sci Med. 2018;215:152-9.

157. Lin CS, Hsu MYF, Chong CF. Differences between emergency patients and their doctors in the perception of physician empathy: implications for medical education. Educ Health (Abingdon). 2008;21(2): 144.

158. Kemper KJ, Schwartz A, Wilson PM, Mahan JD, Schubert CJ, Staples BB, et al. Burnout in pediatric residents: three years of national survey data. Pediatrics. 2020;145(1).

159. Porthe V, Vargas I, Ronda E, Malmusi D, Bosch L, Vazquez ML. Has the quality of health care for the immigrant population changed during the economic crisis in Catalonia (Spain)? Opinions of health professionals and immigrant users. Gac Sanit. 2018;32(5):425-32.

160. Gilligan MC, Osterberg LG, Rider EA, Derse AR, Weil AB, Litzelman DK, et al. Views of institutional leaders on maintaining humanism in today's practice. Patient Educ Couns. 2019;102(10):1911-6.

161. Hayuni G, Hasson-Ohayon I, Goldzweig G, Bar Sela G, Braun M. Between empathy and grief: The mediating effect of compassion fatigue among oncologists. Psychooncology. 2019;28(12):2344-50.

162. Kealy D, Halli P, Ogrodniczuk JS, Hadjipavlou G. Burnout among Canadian psychiatry residents: a national survey. Can J Psychiatry. 2016;61(11):732-6.

163. Passalacqua SA. "Running on empty": examining the effect of physician stress, burnout, and empathy on patient-centered communication during the long-call shift. Diss Abstr Int. 2011;71(11-A):3856.

164. Salyers MP, Flanagan ME, Firmin R, Rollins AL. Clinicians' perceptions of how burnout affects their work. Psychiatr Serv. 2015;66(2):2047.

165. Walocha E, Tomaszewski KA, Wilczek-Ruzyczka E, Walocha J. Empathy and burnout among physicians of different specialities. Folia Med Cracov. 2013;53(2):35-42.

166. McManus IC, Jonvik H, Richards P, Paice E. Vocation and avocation: leisure activities correlate with professional engagement, but not burnout, in a cross-sectional survey of UK doctors. BMC Med. 2011;9:100

167. Roze des Ordons AL, MacIsaac L, Hui J, Everson J, Ellaway RH. Compassion in the clinical context: constrained, distributed, and adaptive. J Gen Intern Med. 2020;35(1):198-206.

168. Bishop JP, Perry JE, Hine A. Efficient, compassionate, and fractured: contemporary care in the ICU. Hastings Cent Rep. 2014;44(4):35-43.

169. Kerasidou A. Empathy and efficiency in healthcare at times of austerity. Health Care Anal. 2019;27(3):171-84.

170. Rider EA, Gilligan MAC, Osterberg LG, Litzelman DK, Plews-Ogan M, Weil AB, et al. Healthcare at the crossroads: the need to shape an organizational culture of humanistic teaching and practice. J Gen Intern Med. 2018;33(7): 1092-9. 
171. Kerasidou A, Kingori P. Austerity measures and the transforming role of $A \& E$ professionals in a weakening welfare system. PLoS One. 2019; 14(2):e0212314

172. Lases LSS, Arah OA, Busch ORC, Heineman MJ, Lombarts KMJMH Learning climate positively influences residents' work-related well-being. Adv Health Sci Educ Theory Pract. 2019;24(2):317-30.

173. van Hoorn BT, Menendez ME, Mackert M, Donovan EE, van Heij1 M, Ring D. Missed empathic opportunities during hand surgery office visits. Hand. 2019.

174. Meeuwesen L, Harmsen JAM, Bernsen RMD, Bruijnzeels MA. Do Dutch doctors communicate differently with immigrant patients than with Dutch patients? Soc Sci Med. 2006;63(9):2407-17.

175. Kennifer SL, Alexander SC, Pollak KI, Jeffreys AS, Olsen MK, Rodriguez KL, et al. Negative emotions in cancer care: Do oncologists responses depend on severity and type of emotion? Patient Educ Couns. 2009;76(1):51-6.

176. Johnson Shen M, Ostroff JS, Hamann HA, Haque N, Banerjee SC McFarland DC, et al. Structured analysis of empathic opportunities and physician responses during lung cancer patient-physician consultations. J Health Commun. 2019;24(9):711-8.

177. Stein HF. 'Sick people' and 'trolls': a contribution to the understanding of the dynamics of physician explanatory models. Cult Med Psychiatry. 1986;10(3):221-9

178. Bertakis KD, Azari R. Patient-centered care: the influence of patient and resident physician gender and gender concordance in primary care. J Womens Health (Larchmt). 2012;21(3):326-33.

179. Pollak KI, Arnold R, Alexander SC, Jeffreys AS, Olsen MK, Abernethy AP, et al. Do patient attributes predict oncologist empathic responses and patient perceptions of empathy? Support Care Cancer. 2010;18(11):1405-11.

180. Rubinstein G, Bentwich ME. The enemy as a patient: what can be learned from the emotional experience of physicians and why does it matter ethically? Dev World Bioeth. 2017;17(2):100-11.

181. Park J, Saha S, Han D, Beach MC. Emotional communication in HIV care: an observational studyofpatients' expressed emotional needs. J Gen Intern Med. 2018;33(2 Supplement 1):181-2.

182. Battegay M, Weber R, Willi J, Eich D, Siegenthaler W, Luthy $\mathbf{R}$. Exploring the doctor-patient relationship reduces staff stress and enhances empathy when caring for AIDS patients. Psychother Psychosom. 1991;56(3): 167-73.

183. Polonsky WH, Belton A, Down S, Capehorn M, Gamerman V, Nagel F, et al. Physicians' challenges when discussing the type 2 diabetes diagnosis with patients: Insights from a cross-national study (IntroDiaTM). Diabetologia. 2014;57(1 SUPPL. 1):S424.

184. Bylund CL, Makoul G. Examining empathy in medical encounters: an observational study using the empathic communication coding system. Health Commun. 2005;18(2):123-40.
185. Epstein RM, Hadee T, Carroll J, Meldrum SC, Lardner J, Shields CG. "Could this be something serious?" Reassurance, uncertainty, and empathy in response to patients' expressions of worry. J Gen Intern Med. 2007;22(12):1731-9.

186. Butalid L, Bensing JM, Verhaak PFM. Talking about psychosocial problems: an observational study on changes in doctor-patient communication in general practice between 1977 and 2008. Patient Educ Couns. 2014;94(3):314-21.

187. Roth CS, Burgess DJ, Mahowald ML. Medical residents' beliefs and concerns about using opioids to treat chronic cancer and noncancer pain: a pilot study. J Rehabil Res Dev. 2007;44(2):263-70.

188. Muggleton J, Guy H, Howard R. Breaking the taboo: an interpretative phenomenological analysis of healthcare professionals' experience of caring for palliative patients with disgusting symptoms. BMJ Support Palliat Care. 2015;5(2):189-95.

189. Lebowitz MS, Ahn W-k. Effects of biological explanations for mental disorders on clinicians' empathy. PNAS. 2014;111(50):17786-90.

190. Fernando AT, Arroll B, Consedine NS. Enhancing compassion in general practice: it's not all about the doctor. $\mathrm{Br} \mathrm{J}$ Gen Pract. 2016;66(648):340-1.

191. Flores R, Brown P. The changing place of care and compassion within the English NHS: an Eliasean perspective. Social Theory \& Health. 2018;16(2):156-71

192. Rydon-Grange M. Psychological perspective on compassion in modern healthcare settings. Journal of medical ethics. 2018;44(11):729-33.

193. Asch SM, Atkins DV, Walling A. If kindness were a drug, the FDA would approve it. J Gen Intern Med. 2020;36:263-4.

194. Fernando AT, 3rd, Consedine NS. Beyond compassion fatigue: the transactional model of physician compassion. Journal of pain and symptom management. 2014;48(2):289-98.

195. Crawford P, Brown B, Kvangarsnes M, Gilbert P. The design of compassionate care. Journal of clinical nursing. 2014;23(23-24):3589-

196. Elayyan M, Rankin J, Chaarani Mw. Factors affecting empathetic patient care behaviour among medical doctors and nurses: an integrative literature review. Eastern Mediterranean health journal = La revue de sante de la Mediterranee orientale = al-Majallah al-sihhiyah li-sharq al-mutawassit. 2018;24(3):311-8.

197. Kelle U. Combining qualitative and quantitative methods in research practice: purposes and advantages. Qual Res Psychol. 2006;3(4):293311.

Publisher's Note: Springer Nature remains neutral with regard to jurisdictional claims in published maps and institutional affiliations. 